\title{
Heboidophrenia and Pseudo-Psychopathic Schizophrenia: Current Knowledge and Critical Perspective
}

\author{
Louis De Page $^{\mathrm{a}}$ Jérôme Englebert ${ }^{\mathrm{b}}$ \\ a Mediter Psychotherapy Centre, Halle, Belgium; ${ }^{b}$ Département de Psychologie, University of Liège, Liège, Belgium
}

\section{Keywords}

Heboidophrenia - Pseudo-psychopathic schizophrenia .

Schizophrenia - Psychosis · Conduct disorder .

Psychopathy · Antisocial personality disorder

\section{Abstract}

In this article, based on literature review, we present an integrated description of heboidophrenia and pseudo-psychopathic schizophrenia. Both diagnostic constructs describe latent psychotic processes inextricably bound with psychopathic features. Although both have been described in different eras and research threads, they are that similar that we could not find divergences. We formulated operational criteria for clinical and research purpose. The recognition of this syndrome improves risk management, treatment, and legal decisions.

\section{Introduction}

Heboidophrenia (Hd) [1] and pseudo-psychopathic schizophrenia (PPS) [2] are more than a mere co-occurrence of schizophrenia $(\mathrm{Sz})$ and psychopathy $(\mathrm{PP})^{1}$. Despite the far-reaching clinical, forensic, and legal implications of both syndromes, and their ever-present relevance, they seem to have been on and off-radar continuously. The present paper examines the convergence of both concepts which have been described in separate research traditions and eras, and presents an operational definition.

Kahlbaum proposed the construct of "heboidophrenia" as a milder, less severe "hebephrenia," implying a "less stormy course, mood changes, and little or no intellectual impairment, confusion, or weakness of mind (than hebephrenia)" [1]. With a clear idea of a "hebetic

\section{KARGER}

(C) 2018 S. Karger AG, Basel

E-Mail karger@karger.com

www.karger.com/psp
Louis De Page

Mediter Psychotherapy Centre

Bergensesteenweg 69

BE-1500 Halle (Belgium)

E-Mail Louis.de.page@gmail.com 
continuum," Kahlbaum described this syndrome for "the young," hence the prefix "hebe" (late adolescents, early adulthood), where delusional ideas are missing, where thinking "passes the point," and where conduct disorders are frequent. Kahlbaum asserts a good treatability and prognosis. Kahlbaum's ideas gained little interest after publication, but surfaced in the 1920s forensic French literature $[5,6]$.

Dunaif and all of which had conduct disorders as children, several legal charges, and marginal adjustment at best throughout free life, and were finally convicted for sexual offenses. They observed that (1) psychotic episodes are not reactive to situations, the reactive elements are exacerbating stimuli to a continuous underlying (latent) schizophrenic disorder, (2) they undergo a more or less rapid return to a compensated state or to an adjustment on a lower level of functioning (no severe deterioration, but no full remission), and (3) the why of the acting-out behavior only illuminates some of the motives behind the criminal act; it does not explain why the conflictual situation seeks solution in the acting-out. Despite its more recent origin, PPS has known little interest, but remains present in the International Classification of Disease as a variant of the schizotypal personality disorder [7].

Authors of both research tradition have presented numerous case studies of highly similar patients. The purpose of this study is to examine the convergences of both constructs and derive a common operational definition for clinical and research purposes, discuss risk and treatment issues, and present supporting evidence in published empirical research.

\section{Method}

The aim of our literature search was to identify all papers pertaining to Hd, PPS, or comorbid Sz (or psychosis) and PP (or antisocial personality and conduct disorder). The following types of papers were included: theoretical dissertations, case studies, historical accounts, empirical investigations, including gray literature such as unpublished manuscripts and conference presentations. Multiple databases were searched (Google Scholar, PubMed, Scopus, and PsycINFO). Authors of unpublished manuscript were contacted in order to obtain full texts. Additional articles were searched for by examining reference lists. We found 32 documents, Hd $(n=21)$ and PPS $(n=12)$, which provide meaningful clinical or theoretical information, not mere references.

We grouped our findings into 4 categories: (a) semiological convergences, (b) risk for violence, (c) treatment and prognosis, and (d) supporting empirical research. Although clinical descriptions are similar throughout publications, these have been formu- lated with very different vantage points (ranging from early case descriptions from French psychiatrists in the 1920s to clinical studies in the 1950s in the United States), and long before the more consistent work fuelled by Hare's Psychopathy Checklist [3].

\section{Results}

We did not find evidence of diverse semiology (Table 1). The European tradition focused on (historical) nosology debates of Hd [5, 8-12] and the careful study of index offenses ("passage à l'acte") through which they enter forensic care $[10,11,13]$. The American tradition, using the concept of PSS, focused on experimental and follow-up studies $[14,15]$ and the adaptive defensive functioning [16]. The bulk of the "European" literature stems from the 1920s, while the "American" literature started in the 1950s.

Both traditions heavily emphasize the latent or forme frustre aspect of the psychosis, and its swings with conduct disorders and PP traits. The difference between publications and authors reflect different quantitative and qualitative nuances in psychodynamics between psychosis and PP traits.

\section{Clinical Symptoms and Criteria}

An Attenuated or Latent Form of Sz: as is evidenced by the lack of delusions and hallucinations $[1,14,17,18]$ (Table 1$)^{2}$. Although Kahlbaum stated that these patients do not have delusions nor hallucinations, subsequent authors are less strict on this matter. General consensus suggest that they have infrequent florid outbursts, but a continuous latent schizophrenic process. They might have mildly formed delusions (perhaps of a transitory nature). These tend to be spoken of, but not experienced emotionally [19]. These patients give an impression of defensive containment about their psychotic experiences if they have any. Occasional florid outburst are not reactive to situations and are often brief $[2,20]$. Vague, pervasive, and persisting anxiety and unstable or rapidly shifting neurotic symptoms (pan-neurosis and pan-anxiety) are often reported as a main manifestation in early literature $[2,10,13,14,21,22]$.

\footnotetext{
${ }^{2}$ We included articles describing or contributing to the description of both syndromes. When an author endorsed views or descriptions of other/previous authors, these were also coded in this table in order to provide a sense of agreement across publications. Clinical features not consistently reported, were grouped in secondary clinical signs.
} 
Table 1. Semiology of $\mathrm{Hb}$ and PPS, suggested operational criteria of lifetime diagnosis, and sources

$$
\begin{array}{llllllllllllllllllll}
1 & 2 & 3 & 4 & 5 & 6 & 7 & 8 & 9 & 10 & 11 & 12 & 13 & 14 & 15 & 16 & 17 & 18 & 19 & 20
\end{array}
$$

\section{Latent schizophrenia}

No firm delusions, no hallucinations

Rarely florid, quick to return to compensated state

Psychotic experience provoke little emotional distress

Cognition

Generally intact, no complete deterioration

Inconsistent use of cognitive abilities, bad judgment

Idiosyncratic moral understandings and logical reasoning

Conduct disorder

Starting in adolescence (or earlier)

Offenses lack of utility, not thought through

General antagonism, oppositional nature

Vagrancy, absconding, wandering

Psychopathic traits

Cheating, impulsive, lying, superficial, callous

Early and lifetime maladjustment features

Lack conflict within themselves, but (intentional) opposition

Can be more acting-out/assaultive

Interpersonal and emotional style

Isolated, asocial, dissocial, schizoid

Negativistic, pessimistic, sulky, or unruly

Torpid autism: insensitive to affective bonds, loss of pleasure

Oscillate between inertia, loss of interest, lack of affect, emptiness and labile, agitated and jumpy episodes

Psychodynamics developmental pathways

Defensive hypothesis

Process or cycling hypothesis

The prodromal hypothesis

Columns in gray refer to PPS publications. Other columns refer to Hb. 1, Kahlbaum, 1890; 2, Rinderknecht, 1920; 3, Halberstadt, 1925; 4, Capgras et al., 1927; 5, Guiraud, 1927; 6, Heuyer and Serin, 1930; 7, Kaplan, 1952; 8, Dunaif and Hoch, 1954; 9, Soccaras, 1957; 10, Bender, 1958; 11, Guttmacher, 1961; 12, Carraz, 1968; 13, Chazaud, 1983; 14, Garrabé, 1996; 15, Durst et al., 1997; 16, Garrabé, 2001; 17, Stanghellini, 2004; 18, Foullu and Estingoy; 19, Coulon and Walter, 2006; 20, Haustgen, 2013.

Hb, heboidophrenia; PPS, pseudo-psychopathic schizophrenia.

Patients cannot offer detailed, causal, or structured explanations for their apparition.

Cognition: three aspects that are repeatedly cited through literature. First, their cognition is generally intact, the schizophrenic cognitive decline is less severe, but both a full blown deterioration and remission are inhibited $[1,5,10,14,20,23,24]$. Second, the use of their intellectual abilities is inconsistent and discordant $[19,25]$. Finally, their moral understanding can be highly idiosyncratic as is evidenced by a particular way to distinguish what is right and what is wrong, or faulty logic [19]. For example, a patient otherwise capable of logic reasoning reported that he did not understand why it was "wrong" to rape women who he accepted to shelter for a night, but that it would be wrong if he had not accepted to shelter them.

Conduct Disorders and Antisocial Behavior: beginning with puberty, are proposed as a manifestation of the latent schizophrenic process [19, 24-26]. These behaviors are not thought through and lack in utility, benefit, and tenacity [2]. Patients offer vaguely coherent explanations, but they do not stand a more in-depth confrontation with reality [19]. The scope of their antisocial behavior is immediately determined by their direct surrounding. Therefore, antisocial tendencies tend to be curbed by supervision and admissions into hospitals, 
and might therefore go unrecognized at admission [16, 27]. Their antagonism and oppositional tendencies, whether passive or active, are often noticed in school or in family, and then quietly proliferate through adulthood in society until spotted by authorities [19]. Absconding and wandering are often reported; they tend to abruptly subtract themselves from context where they have not been able to find fulfilment. These patients reach a marginal adjustment at best (vagrancy, prostitution, alcoholism, deviant/criminal, and so on) $[2,13$, 18-21].

Psychopathic Personality Traits: such as unreliability, unruliness, impulsiveness, anger, cheating, bullying, bad judgment, malice, inability to profit from experience, disregards for truth, and so on are characteristic $[2,14,20$, $27,28]$. They often act intentionally in a rebellious way or bully care-givers such as nurses [27]. These symptoms are not transient nor episodic. Authors emphasize lifestyle and early development rather than flamboyant PP personality such as eloquence, charmingly manipulative, or grandiose sense of self. Their psychopathic features revolve around passive opposition, lack of guilt, and remorse. During interviews they are described as evasive and circumstantial, defensively contained, and affectively shallow. Although a subgroup of patients is markedly more assaultive, this is not systematic.

Interpersonal and Emotional Relations: these patients are isolated and asocial $[10,14]$. They are perceived as negativistic, sulky ("boudeurs"), pessimistic, oppositional, or unruly [8, 22, 27, 29]. Several authors delineate a "morose/torpid form of autism," constructing a dynamic whereby they live on their own, insensible to affective bonds, loss of pleasure, withdrawal on their own $[2,10$, $14,18,20,22]$. Other case studies report an oscillation between inertia, loss of interest, lack of affect, emptiness $[5,10,11,30]$ on one hand, and labile, variable, and jumpy episodes on the other hand $[2,20,22,24]$.

Secondary Clinical Symptoms and Correlates: alcohol and substance use are present in many case studies $[2,13$, 14 ], but about $60 \%$ of schizophrenic patients [31] and up to $52 \%$ of antisocial personality disordered (ASPD) individuals have a diagnosis of alcohol or substance abuse [32]. Troubled sexuality has often been reported [2, 14], but a specific sexual pattern to Hd/PSS cannot be ascertained [33]. Psychopaths show a strong sexual drive while schizophrenia patients often experience impairments in addition to reduced sexual desire $[14,34]$. Stereotyped behavior patterns are often absorbed routinely in these people, sometimes as sterile or apragmatic behaviors $[10$, $13,27,29,33]$. Hypochondrial trends have been reported in some patients. Bizarre physical complaints might serve as an expression of psychotic phenomena $[2,12$, 14].

\section{Psychodynamics and Developmental Pathways}

Different developmental or psychodynamic pathways specific to Hd/PPS have been described. We have been able to distinguish 3 groups. Many authors use a conjecture of these hypotheses.

Defensive Hypothesis: the psychopathic dynamic serves as a shield against disorganizing effects of $\mathrm{Sz}[10,12,19$, $25,29,30]$. When successful, "anxiety is handled so well that it ceases to be overt and neurotic defenses are no longer needed, and intellectual functioning is increased" [25]. This hypothesis can work proactively, but also retroactively: "chronic psychotic patients may develop the capacity to bend the course of (their) psychosis to (their) will, forcing it to serve their practical needs. In these instances, we deal with sociopathic adaptions reactive to psychotic outbursts" [16]. Antisocial tendencies can be considered as a temporary dominance of defensive instincts [19]. The defensive hypothesis relies upon an assumed hierarchy in maturity of personality functioning: $\mathrm{Hd} / \mathrm{PPS}$ patients defend themselves from disaggregation with reactional conduct stemming from more mature dynamic organizations. These views rely upon the work of Minkowski who indicated the existence of schizophrenic attitudes which enabled to resist disaggregation [35].

Process or Cycling Hypothesis: psychopathic and psychotic dynamics trigger each other in a cycling manner $[2,8,12,22,30]$. Beck sharpened this defensive cycle as follows: "(a) phase of serious personality disorder, followed by (b) a stabilizing and apparent integration of their personalities, and lasting over a period of years; but following in turn by (c) either a new breakdown which is of psychotic proportion, or by very delinquent behavior" [25]. Both components trigger each other because the PP functioning has a disorganizing effect upon the psychotic core of their personality $[8,22]$, but at the same time antisocial behavior predominates in periods of remission [36]. In our clinical experience, this dynamic often revolves around paranoid features, whereby the psychopathic functioning is an active variant of the paranoid persecutory position, and is further facilitated by disordered mood regulation [12, 37].

The Prodromal Hypothesis: Kahlbaum considered conduct disorders as an early sign of the underlying psychotic process. Psychopathic traits and antisocial conduct are seen as a prodromal stage $[1,8,17,19,20,26]$. This view considers Hd/PPS as a pre-psychotic state 
whose process persists in a discrete fashion, and is occasionally augmented by paroxistic/symptomatic periods [19].

\section{Differential Diagnosis}

Compared to Hd/PSS, PP as children tend to be oppositional, lack empathy, and be cold-hearted while the $\mathrm{Hd} /$ PPS children are less disturbed [19, 38-41]. Offense committed by PP have clear personal gain and self-preservation is calculated [19]. Hd/PSS subjects are antisocial and asocial as well, withdrawing from others. The true PP is definitely social [14]. The Hd/PPS patient may be paranoid as a result of reactions conceived within; the socalled paranoid reactions in the true psychopath relate only to interference encountered in the immediate environment [14].

The differential diagnosis between Hd/PPS and $\mathrm{Sz}$ is not merely quantitative. Motives for offenses committed by $\mathrm{Sz}$ are either nonexistent or frankly delusional [19]. $\mathrm{Hd} / \mathrm{PPS}$ have a pseudo-logic explanation for their offenses. If present, paranoid cognitions are latent and not necessarily connected with violence [11]. The magnitude of their delusions and conviction strength, if they are present hitherto, is inferior in Hd/PPS. Conduct disorders are the main extraversion of the psychotic process, while in $\mathrm{Sz}$, they represent a fragment of psychotic signs [19].

\section{Risk}

$\mathrm{Hd} / \mathrm{PPS}$ reflect a subgroup of individuals prone to violence and offending with major mental disorders $[13,42]$. Risk in Hd/PPS is higher than in Sz, and does not appear to diminish as their psychosis stabilizes $[13,30]$. The probability of violence or general offending is often independent of their clinical state. Offenses are polymorphous ranging from simple theft [43] to sexual abuse [2], misuse of psychiatric facilities $[22,30]$, and so on. With regard to hospitals, they can abuse other patients, and deplete staff patience $[19,20,22,30,44]$. They can be very manipulative [16]; "in periods of schizophrenic remission, these patients take legal advantage of their mental illness, break the law with impunity and escape prosecution owing to insanity" [22]. Their delinquent side often grabs the attention more than their psychotic side; danger to themselves is often neglected. The risk stems from the phenotypical versatility; "they swing from perversion, to an autistic state, to a sociopathic condition," "they are unpredictable, they jump for trivial reasons, they may boil over, or get over-agitated. Other times they may fall prey to malicious impulsiveness" [18].

Hd and PPS

\section{Treatment and Prognosis}

The prognosis is good so far as the degenerative influence of schizophrenia is halted, but the improvement by therapy is limited due to the psychopathic features [ 1 , $14,36,45]$. The prognosis is influenced by the severity of the conduct disorder: severe behavioral disturbances lead to prison and security services, while minor disturbances enable to wait until natural improvement in adult age [9]. Age has been reported as a protective factor [19].

Despite overall therapeutic pessimism, all authors agree on the need of constant judicial supervision in addition to care $[13,22,46]$, if only to prevent progress in criminal careers. Psychopharmacological treatments and responses have only been discussed in a few articles [14, $19,47]$. Judicial third-party evaluators are useful to triangulate and enforce credibility of care-givers [13].

Careful examinations of their history reveals that families often unsuccessfully tried to bring these patients to care $[13,19]$. These patients have great difficulty forming therapeutic alliance; during psychotherapy little insight is gained and a dearth of ideas and associations is frequently observed $[12,14]$.

\section{Supporting Empirical Research}

Only a few studies have involved actual Hd/PPS patients $[15,19,30,45]$. Hypotheses regarding a less severe cognitive decline, the mixed prognosis, and less symptomatic patients were supported. Only a few studies reported prevalence: $1-2 \%$ in a general psychiatric hospital, and $7 \%$ in a forensic psychiatric ward for psychosis.

Supporting evidence can be found in broader literature on comorbid Sz and ASPD or PP. Reported comorbidity between PP and $\mathrm{Sz}$ in forensic patients is $23-33 \%$ [44]. Schizophrenic patients with high PP traits had higher mean number of previous offences, have less self-control, are less compliant, more coercive, hostile, higher mean total risk estimates, have more resentment, are more assaultive, deviant, and impulsive. Tengström et al. [42] asserted that symptoms of illness are more important than PP for the accuracy of violence prediction. In longterm prediction, the PP assessment becomes a better predictor of violence.

The prodromal hypothesis is supported by the Coté and Hodgins [48] who identified a subgroup of offenders with major mental disease, where antisocial behavior precedes the onset of $\mathrm{Sz}$ by many years. Furthermore, violence of young criminals predicts $\mathrm{Sz}$ at $3.3 \%$ and any psychosis at $4.5 \%$ [49]. 
We must be aware that many of these studies are structured in the perspective of violence. Although this group is probably more assaultive, the risk is polymorphous and focusing on this literature might divert us from the discreet, less violent cases [12]. Publications on schizophrenia and PP (or ASPD) focus on lifetime overtly psychotic patients and PP identified through the Psychopathy Checklist-Revised (PCL-R, [3]). Hb/PPS patients are likely to be excluded from these studies because of the latent psychotic process. However, these patients might be included in PP (or ASPD) samples and studies, because they are misdiagnosed $[2,46]$.

\section{Discussion}

Despite its ever-present relevance in forensic settings, these diagnoses have fallen into oblivion for different reasons. Therefore, these patients receive a "hospital diagnosis," and are described as PPS/Hb later in case studies. These diagnoses are based on a diachronic, psychodynamic basis rather than clinical symptomatology [20,45]. Because conduct disorders are one of the main signs of their illness, they cannot always be diagnosed when they have been stationary for a long time [19]. Contrary to schizophrenia and other psychoses (such as defined in the DSM for example [50,51]), firm delusions and hallucinations cannot be considered as central nor sufficient diagnostic hallmarks. Hb/PPS is epidemiologically infrequent but clearly distinct in semiology from other schizophrenic processes. In addition, the separation of psychopathology versus personality introduced by the DSM makes it difficult for a syndrome who mixes both to gain recognition $[22,52]$. The lack of an operational definition, which we hope to help solve, and the lack of actual empirical research, which we hope will be conducted, have probably contributed to the little interest in these diagnoses.

Kalhbaum's original definition cannot be integrally sustained in the light of a century of research on this diagnosis. Contrary to Kahlbaum's assertion, Hb/PPS patient can have transient hallucinations and loosely defined delusion $[1,5,13,20]$. The age of occurrence is situated in early adulthood by Kahlbaum, but subsequent research support the lifetime character of the construct $[5,14,22]$. More generally speaking, Kahlbaum proposed the diagnosis as a "lighter" version of hebephrenia, while literature insists on the severe but less overt nature of the condition $[2,22,28,29]$.

The construct and assessment of PP in $\mathrm{Sz}$ is a sensitive topic. Some authors contend that the validity of the PP construct has not been properly established $[42,44,53$, 54]. The apparent resemblance between $\mathrm{Sz}$ and PP features complicates the assessment (e.g., flat affect, hostile and paranoid ideations, etc.). Notwithstanding, assessing $\mathrm{PP}$ in $\mathrm{Sz}$ has improved risk assessment $[42,55]$. Therefore, it is important to distinguish a syndrome in which PP features are structurally integrated into the psychotic process, especially for the assaultive correlates $[5,13,14]$. Leaving the PP features inherent to $\mathrm{Hb} / \mathrm{PPS}$ unrecognized, is incurring a substantial risk of violence and offending.

Given the clear legal and forensic implications of this diagnosis, we would not be complete if legal responsibility was not discussed. We think that the question of intentionality is central in this debate: psychopaths are considered legally responsible, while schizophrenics are not. Hd/PPS commit offense from either core. Durst et al. [22] argued that the concept of Hd/PPS enables to present, with conceptual clarity, why a psychiatric evaluation of criminal culpability can change from one assessment to another, at different times. We do agree that psychosis is best treated by mental health services, whereas sociopathic behavior is better handled through behavioral approaches, or dealt by legal authorities. In any case, $\mathrm{Hd}$ /PPS patients are not necessarily irresponsible $[20,56]$. Given the fact that health services are the preferred choice in case of doubt [20], it is important to have a clear diagnostic framework.

\section{Conclusion}

The current review of literature suggests that Hd and PPS are highly similar constructs. We integrated findings from different literature threads in order to present operational diagnostic criteria, risk-related issues, treatment perspectives, and supporting evidence. The diagnosis of Hd/PPS does not broaden the concept of $S z$ [19, 22]. It filters a specific subgroup with distinctive psychopathological dynamics and risk correlates from a broader comorbid group [31]. The use of this diagnosis might enable a better triage [13], acknowledges subtleties in legal responsibility debates, and prevent abuse of psychiatric facilities [22].

\section{Acknowledgments}

We kindly thank Caroline Valentiny and Gosig Rât for their helpful review on the early draft of this manuscript. 


\section{References}

1 Kahlbaum K: On heboidophrenia. Allg Z Für Psychiatr 1890;46:461-471.

2 Dunaif S, Hoch PH: Pseudopsychopathic schizophrenia; in Psychiatry and The Law. New York, Grune \& Stratton, 1954, pp 169-195.

3 Hare RD: The Hare Psychopathy ChecklistRevised: Manual. Toronto, Multi-Health Systems, Inc., 1991.

4 Cooke DJ, Hart SD, Logan C, Michie C: Explicating the construct of psychopathy: development and validation of a conceptual model, the Comprehensive Assessment of Psychopathic Personality (CAPP). Int J Forensic Ment Health 2012;11:242-252.

5 Coulon N, Walter M: L’héboïdophrénie, un diagnostic oublié? Rev Francaise Psychiatr Psychol Méd 2006;10:29-34.

6 Garrabé J: Schizophrénies et héboïdophrénie. Evol Psychiatr (Paris) 2001;66:609-613.

7 World Health Organization: The ICD-10 Classification of Mental and Behavioural Disorders: Diagnostic Criteria for Research, 1993.

8 Ey H, Bernard P, Brisset C: Manuel de Psychiatrie, 1972

9 Garrabéj:Notehistoriquesurl'héboïdophrénie. Evol Psychiatr (Paris) 1996;61:75-85.

10 Guiraud P: Constitution perverse ou héboïdophrénie. Bull Soc Clin de Med Ment 1927; 89-92.

11 Guiraud P: Les meurtres immotivés. LÉvolution Psychiatr 1931;4:25-34.

12 Soccaras E: Schizophrénie pseudo-névrotique et schizophrénie caracterielle. Rev Fr Psychanal 1957;21:535-552.

13 Foullu S, Estingoy P: De l'intérêt clinique du concept d'héboïdophrénie. À propos de deux cas de schizophrénie criminelle. Ann MédPsychol Rev Psychiatr 2006;164:756-763.

14 Kaplan H: The schizophrenic reaction with psychopathic features: clinical characteristics and response to therapy: a comprehensive study of seven cases. AMA Arch Neurol Psychiatry 1952;68:258-265.

15 Stephens JH, Astrup C: Prognosis in "process" and "non-process" schizophrenia. Am J Psychiatry 1963;119:945-953.

16 Geller MP: Sociopathic adaptations in psychotic patients. Psychiatr Serv 1980;31:108-112.

17 Kraam A, Berrios G: On Heboïdophrenia. Hist Psychiatry 2002;13:197-208.

18 Stanghellini G: Psychopathological roots of early schizophrenia: adolescent vulnerability, hebephrenia and heboidophrenia. Curr Opin Psychiatry 2004;17:471-477.

19 Carraz YC: L’héboïdophrénie, 1968.

20 Halberstadt G: La forme héboïdophrénique de la démence précoce. Ann Méd Psychol 1925;II:23-32.

21 Benon R: Démence précoce et vagabondage. Ann Hygiène Publique Médecine Légale 1923;4:90-96.

22 Durst R, Jabotinsky-Rubin K, Fliman M: Pseudopsychopathic schizophrenia - a neglected diagnostic entity with legal implications. Med L 1997;16:487-498.
23 Haustgen T: Le concept clinique d'héboïdophrénie; in Masson M (ed): 24 Textes Fondateurs de la Psychiatrie Introduits et Commentés par la Société Médico-Psychologique. Paris, Armand Colin, 2013.

24 Rinderknecht G: Über kriminelle Heboide. Z Für Gesamte Neurol Psychiatr 1920;57:35-70.

25 Bender L: The concept of pseudopsychopathic schizophrenia in adolescents. Am J Orthopsychiat 1959;29:491-512.

26 Heuyer MG, Serin: Les troubles du caractère au début de la démence précoce. Ann Méd Psychol 1930;2:90-110.

27 Capgras, Dupouy, Briau: Délire malicieux héboïdophrénique. Ann Méd-Psychol 1927; 2:360-372.

28 Guttmacher M: Pseudopsychopathic schizophrenia. Arch Crim Psychodyn Spec Psychopathy Issue 1961;502-508.

29 Chazaud J: Hystérie, Schizophrénie, Paranoïa: Chemins Vers une Psychiatrie Psychanalytique. Toulouse, Privat, 1983.

30 De Page L, Titeca P: Psychopathy and Psychosis: A Hazardous Interplay and Questionnable Treatment, 2014.

31 Volavka J, Citrome L: Heterogeneity of violence in schizophrenia and implications for long-term treatment. Int J Clin Pract 2008;62: 1237-1245.

32 Trull TJ, Jahng S, Tomko RL, Wood PK, Sher KJ: Revised NESARC personality disorder diagnoses: gender, prevalence, and comorbidity with substance dependence disorders. J Personal Disord 2010;24:412-426.

33 Henderson MC, Kalichman SC: Sexually deviant behavior and schizotypy: a theoretical perspective with supportive data. Psychiatr Q 1990;61:273-284.

34 de Boer MK, Castelein S, Wiersma D, Schoevers RA, Knegtering $\mathrm{H}$ : The facts about sexual (dys) function in schizophrenia: an overview of clinically relevant findings. Schizophr Bull 2015;41:674-686.

35 Claude H, Minkowski E, Tison: Contribution à l'étude des mécanismes schizophréniques. L'Encéphale 1925;2-13.

36 Kernberg: Diagnóstico diferencial de la conducta antisocial. Rev Psiquiatr Chile 1988;5: 101-111.

37 De Page L, Englebert J: Réflexion Psychopathologique Sur le Diagnostic D’héboïdophrénie, 2016.

38 Bird G, Viding E: The self to other model of empathy: providing a new framework for understanding empathy impairments in psychopathy, autism, and alexithymia. Neurosci Biobehav Rev 2014;47:520-532.

39 Henry J, Pingault J-B, Boivin M, Rijsdijk F, Viding E: Genetic and environmental aetiology of the dimensions of Callous-Unemotional traits. Psychol Med 2016;46:405-414.

40 Frick PJ, Ray JV, Thornton LC, Kahn RE: Can callous-unemotional traits enhance the understanding, diagnosis, and treatment of serious conduct problems in children and adoles- cents? A comprehensive review. Psychol Bull 2014;140:1-57.

41 Muratori P, Lochman JE, Manfredi A, Milone A, Nocentini A, Pisano S, et al: Callous unemotional traits in children with disruptive behavior disorder: predictors of developmental trajectories and adolescent outcomes. Psychiatry Res 2016;236:35-41.

42 Tengström A, Grann M, Langström N, Kullgren G: Psychopathy (PCL-R) as a predictor of violent recidivism among criminal offenders with schizophrenia. Law Hum Behav 2000;24:45-58.

43 Biéder J, Callens H, Alcalay J: À propos du vol "normal" et pathologique. Ann Méd-Psychol 2001;159:131-139.

44 Fullam R, Dolan M: The criminal and personality profile of patients with schizophrenia and comorbid psychopathic traits. Personal Individ Differ 2006;40:1591-1602.

45 Holmesland P, Astrup C: Pseudoneurotic and pseudopsychopathic schizophrenia: a followup. Neuropsychobiology 1984;12:101-105.

46 Dubret G: Quel cadre de soin pour les psychopathes? Evol Psychiatr (Paris) 2001;66:665668.

47 Kernberg OF: Perversion, perversity, and normality: diagnostic and therapeutic considerations. Perversion Psychoanal Perspect Perspect Psychoanal 2006;19-38.

48 Coté G, Hodgins S: Co-occurring mental disorders among criminal offenders. J Am Acad Psychiatry Law Online 1990;18:271-281.

49 Gosden NP, Kramp P, Gabrielsen G, Andersen TF, Sestoft D: Violence of young criminals predicts schizophrenia: a 9-year registerbased followup of 15-to 19-year-old criminals. Schizophr Bull 2005;31:759-768.

50 American Psychiatric Association: Diagnostic and Statistical Manual of Mental Disorders DSM-IV-TR Fourth Edition (Text Revision), 2000.

51 American Psychiatric Association: Diagnostic and Statistical Manual of Mental Disorders $\left(\mathrm{DSM}-5^{\circledR}\right)$. Arlington, American Psychiatric Pub, 2013.

52 Zagury D: Place et évolution de la fonction de l'expertise psychiatrique. Psychopathol Trait Actuels Auteurs D'Agression Sex, 2001.

53 De Page L, Matteucci M, Englebert J: The shortcomings of the Psychopathy ChecklistRevised (PCL-R) in a forensic schizophrenic sample. Ann Méd-Psychol, in-press.

54 Englebert J: A new understanding of psychopathy: the contribution of phenomenological psychopathology. Psychopathology 2015;48: 368-375.

55 Tengström A, Hodgins S, Grann M, LÅngstrÖm N, Kullgren G: Schizophrenia and criminal offending the role of psychopathy and substance use disorders. Crim Justice Behav 2004;31:367-391.

56 Meggendorfer F: Klinische und genealogische Untersuchungen über "Moral insanity." Z Für Gesamte Neurol Psychiatr 1921;66:208-231. 